\title{
LA PROCEDENCIA DEL RECURSO DE RECONSIDERACION CONTRA EL INFORME DE PRECALIFICACION DEL PROCEDIMIENTO ADMINISTRATIVO DISCIPLINARIO
}

THE ORIGIN OF THE RESOURCE OF RECONSIDERATION AGAINST THE REPORT OF PRECALIFICATION OF THE DISCIPLINARY ADMINISTRATIVE PROCEDURE

Anthony Hamiltón Cotillo Mogrovejo ${ }^{1}$

\section{RESUMEN}

El rol punitivo del estado peruano no solamente descansa en los cuerpos normativos del código penal y del código procesal penal, sino también en su carácter disciplinario y sancionador dentro de la administración pública, por ende a este último deberá de dotársele de cualidades garantistas propias del proceso penal cuando presente vacíos o deficiencias normativas.

Palabras clave: Procedimiento Administrativo Disciplinario, carácter punitivo, recursos impugnatorios, recurso de reconsideración.

\begin{abstract}
The punitive role of the Peruvian state rests not only on the normative bodies of the penal code and the criminal procedural code, but also on its disciplinary and sanctioning nature within the public administration, so the latter must be endowed with guaranteed qualities of the process Criminal when there are voids or regulatory deficiencies
\end{abstract}

Keywords: Administrative Disciplinary Procedure, punitive character, appeals, reconsideration. 


\section{INTRODUCCIÓN}

El estado peruano en uso de su IUS PUNIENDI, dota a la administración pública de la potestad sancionadora y disciplinaria a fin de salvaguardar el interés público, respetando además los derechos laborales de los servidores estatales; reglamentándose así el nuevo procedimiento administrativo disciplinario, el cual descansa en el cuerpo normativo de la Ley de Servicio Civil Ley $\mathrm{N}^{\circ} 30057$, en su reglamento aprobado mediante Decreto Supremo N 040-2014-PCM y en su Directiva N002-2015-SERVIR/GPGSC aprobada mediante Resolución de Presidencia Ejecutiva $N^{\circ}$ 101-2015-SERVIR-PE, de fecha 20 de marzo del 2015, aplicable a los regímenes laborales de los decretos legislativos $276^{\circ}, 728^{\circ}$ y $1057^{\circ}$.

El procedimiento administrativo disciplinario (En adelante PAD) contiene dos etapas: La etapa instructiva y la etapa sancionadora. La primera inicia con la emisión del acto comúnmente resolutivo que decide instaurar P.A.D a determinado servidor en su propia notificación y culmina con la emisión de un último informe posterior al descargo del servidor denunciado, dando pie además a la etapa sancionadora, la cual finaliza con la decisión de primera instancia. Proveyendo adicionalmente de recursos impugnatorios al servidor procesado a fin de garantizar sus derechos procesales fundamentales. Empero es en la aplicación de estos recursos impugnatorios en sí, el descubrimiento del siguiente vacío normativo, que deja a criterio del aplicador de la norma, su interpretación.

\section{PLANTEAMIENTO DEL PROBLEMA:}

Es la procedibilidad de recurso de reconsideración interpuesto contra el informe de Precalificación del P.A.D. el cual despierta un interés necesario por discutir.

El informe de precalificación es emitido por el secretario técnico de su institución, el mismo que contiene la información de los hechos, del servidor y las actuaciones previas al inicio del P.A.D. esto es las diligencias de investigaciones a partir de la recepción de la denuncia

Ahora bien, el último párrafo del artículo $107^{\circ}$ del reglamento de la ley de Servicio Civil establece que: "El acto de inicio con el que se imputan los cargos, deber ser acompañado con los antecedentes documentarios que dieron lugar al inicio del procedimiento administrativo disciplinario y no es impugnable", es decir que no procede el recurso de reconsideración contra la decisión de instauración del P.A.D. Sin embargo como ya habíamos mencionado este informe es previo a la emisión de dicho acto. Debemos acotar también que el artículo $118^{\circ}$ del mismo reglamento establece que: "El recurso de reconsideración se sustentará en la presentación de prueba nueva y se interpondrá ante el órgano sancionador que impuso la sanción, el que se encargará de resolverlo. Su no interposición no impide la presentación del recurso de apelación", dando la sensación que el recurso de reconsideración solo podrá ser admitido cuando este tenga por finalidad reconsiderar una sanción impuesta. Supuesto que no encaja, toda vez que el informe de precalificación en cuestión, no es emitido en la etapa sancionadora sino muy previo a este.

El recurso de reconsideración se encuentra previsto en el artículo $208^{\circ}$ de la Ley de Procedimiento Administrativo General Ley $N^{\circ} 27444$, la cual establece que: "El recurso de reconsideración se interpondrá ante el mismo órgano que dicto el primer acto que es materia de la impugnación y deberá sustentarse en nueva prueba. En los casos de actos administrativos emitidos por órganos que constituyen única instancia no se requiere nueva prueba. Este recurso es opcional y su no interposición no impide el ejercicio del recurso de apelación“. Habiéndose mencionado todos los artículos pertinentes con los que contamos, resultaría proclive pensar que la inclinación por la improcedencia del recurso de reconsideración posee más sustento ante la ausencia normativa de este supuesto. Es decir, la interpretación sistemática por sí sola, podría dar a entender al aplicador de la norma, que si bien existe una protección contra el acto que decide instaurar P.A.D. con más razón esta protegería el informe previo a este (A maiori ad minus - El que puede los más puede o menos), reforzándose además, que la ley prevé que este recurso impugnatorio solo es atendible cuando busca reconsiderar una sanción impuesta, por lo tanto debería ser declarado improcedente.

Sin embargo a criterio del autor de la presente, este primer supuesto solo podría tomar validez siempre y cuando el informe de precalificación emitido por el Secretario Técnico recomienda el inicio de P.A.D. toda vez que el servidor poseerá dentro del proceso las herramientas pre establecidas para su defensa (Descargos, informe oral, pruebas de parte y más). Llevándonos a plantear la siguiente interrogante: ¿Procedería el recurso de reconsideración contra un informe de precalificación que decide el archivamiento de la denuncia?

\section{ANÁLISIS:}

Para resolver el punto más álgido del presente artículo jurídico es menester traer a colación el fundamento 61 de la resolución $\mathrm{N}^{\circ}$ 2249-2012/SC2-INDECOPI, perteneciente al expediente $N^{\circ} 229-2011 / P S-$ INDECOPI-PIU la cual establece que: "La referencia al proceso penal es especialmente útil para el análisis de la cuestión en discusión no solamente porque la potestad punitiva penal como la sancionadora constituyen manifestaciones de un mismo ius puniendi genérico del estado, sino porque el derecho penal opera como ultima ratio, pues la selección entre configuración de una conducta administrativa o delito penal dependerá de trascendencia del acto ilícito que se pretende castigar. Las contravenciones menores son objetos de punición mediantes sanciones administrativas, reservándose el derecho penal las conductas infractoras que impliquen una mayor ofensa al interés público".

Entonces es a partir de un mismo ius puniendi del cual debemos partir para desarrollar la pregunta en 
cuestión. La utilización de la interpretación por especialidad es la que nos permitiría determinar la procedencia del recurso de reconsideración, siendo la analogía con el derecho procesal penal necesaria para simular un P.A.D.; claro está, que este esta ha sido mejor desarrollado por los estudiosos del derecho procesal penal, pero que sin embargo comparten el mismo carácter punitivo innegable.

El titular de ejercicio de la acción penal (Ministerio Publico) actúa de oficio o a instancia de parte, siendo el fiscal quien conduce desde su inicio la investigación del delito (Similitud con la función del Secretario Técnico dentro del P.A.D), pero es este, el que a través de su requerimiento mediante por el cual decide judicializar o no la investigación. Por lo tanto la decisión del archivamiento de una denuncia en sede fiscal, posee el estado de cosa decidida fiscal (Término acuñado por el Catedrático y Abogado Juan Hurtado Poma). Los efectos de inimpugnabilidad e inmutabilidad de la cosa decida fiscal se exceptúan si es que luego se logran aporta nuevos elementos de convicción, otorgándosele de forma intrínsecas al denunciante una especie de doble instancia al poder reconsiderar la denuncia previamente planteada.

Por lo tanto la decisión del archivamiento o de declarar: "No ha lugar a trámite" de una denuncia interpuesta en sede administrativa en un informe de precalificación por parte de la Secretaria Técnica guarda una fuerte similitud con la decisión de archivamiento en sede fiscal, toda vez que las dos decisiones forman parte de un mismo ius puniendi del estado, debiéndose de integrar las normas establecidas en el proceso penal vigente al vacío normativo que presenta el P.A.D. respetándose así el derecho de todo investigado (Sede Penal - Sede Disciplinaria Administrativa) de solicitar la revisión de las decisiones que de alguna u otra forma causan estado.

\section{REFERENCIAS BIBLIOGRÁFICA:}

Ley de Servicio Civil № 30057

Reglamento de la Ley de Servicio Civil Nº40-2014PCM

Directiva N ${ }^{\circ} 002-2015-S E R V I R / G P G S C$

Resolución N²249-2012/SC2-INDECOPI

La Cosa Decidida en decisión final de archivo Guilliana LozaAvalos 2014

Sobre los argumentos interpretativos - José Antonio Gonzales Flores 